Check for updates

Cite this: RSC Adv., 2019, 9, 1841

Received 12th October 2018 Accepted 18th December 2018

DOI: $10.1039 / c 8 r a 08470 j$

rsc.li/rsc-advances

\section{Low temperature atomic layer deposition of zirconium oxide for inkjet printed transistor applications $\uparrow$}

\author{
Mohi Uddin Jewel, ${ }^{a}$ MD Shamim Mahmud, ${ }^{a}$ Mahmuda Akter Monne, ${ }^{\text {b }}$ Alex Zakhidov ${ }^{\text {bc }}$ \\ and Maggie Yihong Chen (D) *ab
}

We report the growth of zirconium oxide $\left(\mathrm{ZrO}_{2}\right)$ as a high- $k$ gate dielectric for an inkjet-printed transistor using a low-temperature atomic layer deposition (ALD) from tetrakis(dimethylamido)zirconium (TDMAZr) and water precursors. All the samples are deposited at low-temperature ranges of $150-250{ }^{\circ} \mathrm{C}$. The films are very uniform with RMS roughness less than $4 \%$ with respect to their thickness. The atomic force microscopy (AFM) shows a significant change in surface morphology from tapered posts to undulating mountain-like structures with several hundreds of ALD cycles. The results from X-ray diffraction (XRD) analysis exhibit an amorphous to the crystalline structure with temperature variation, which is independent of the thickness of the films. All our samples are hydrophilic as contact angles are less than $90^{\circ}$. The capacitance-voltage $(C-V)$ and conductance-voltage $\left(G_{\mathrm{p}} / \omega-V\right)$ characteristics of $\mathrm{ZrO}_{2}$ dielectrics for silicon metal-oxide-semiconductor (MOS) capacitors are studied for different temperatures. For the n-type substrate MOS capacitors, the dielectric constants are estimated to be 7.511. Due to the low deposition temperature, a hydrophilic surface, and high $k$ value, the ALD $-\mathrm{ZrO}_{2}$ dielectric can be compatible for printed transistors. The processes of fabrication and characterization of inkjet-printed graphene transistors is demonstrated using the $\mathrm{ZrO}_{2}$ dielectric. The possible solvents, surfactant, and the dielectric induced modifications in graphene flakes are demonstrated by Raman spectra. The graphene flakes spread uniformly on the $\mathrm{ZrO}_{2}$ surface. The functional inkjet-printed graphene transistor characteristics are demonstrated to illustrate the field effect behavior with the ALD$\mathrm{ZrO}_{2}$ dielectric.

\section{Introduction}

Inkjet printing has emerged as a popular technology for printed electronics. ${ }^{1}$ It has many advantages, such as low material wastage, the ability of large area fabrication, a limited number of process steps, low cost, and compatibility with many substrates. ${ }^{2,3}$ Inkjet printed technology for device fabrication is still in its infancy, although significant developments have been reported in printing transistors, memory devices, solar cells, organic light emitting diodes (OLEDs), and sensors. ${ }^{4-8}$ Printed transistors require thin, uniform, and stable gate dielectrics for robust control of the drain current at low temperature.

\footnotetext{
angram School of Engineering, Texas State University, San Marcos, Texas 78666, USA. E-mail: maggie.chen@txstate.edu

${ }^{b}$ Materials Science, Engineering, and Commercialization, Texas State University, San Marcos, Texas 78666, USA

${ }^{c}$ Department of Physics, Texas State University, San Marcos, Texas 78666, USA

$\dagger$ Electronic supplementary information (ESI) available: ALD process, 2D AFM and SEM images of $\mathrm{ZrO}_{2}$ of thickness 38.58, 32.51,22.2 and $46.4 \mathrm{~nm}$ prepared at 150, 200 , and $250{ }^{\circ} \mathrm{C}$; EDS spectra at 150,200 , and $250{ }^{\circ} \mathrm{C}$. Hysteresis in the ALD-ZrO dielectric; graphene ink preparation, UV-vis, and Raman characterization; transfer curves of printed graphene transistor. See DOI: $10.1039 / \mathrm{c} 8 \mathrm{ra08470j}$
}

However, the coffee ring effect on printed patterns causes more flakes aggregation in the perimeter than the center of the defined region. ${ }^{9}$ Consequently, a thick dielectric layer and a high gate voltage are required to introduce field effect behaviors in printed top and back-gated transistors. ${ }^{\mathbf{4 , 1 0 , 1 1}}$ The solution-processed dielectrics are easy to use for printed transistors as they can be deposited at low-temperatures on flexible substrates. ${ }^{\mathbf{1 2}}$ Yet, the application of solution-processed dielectrics are limited due to their instability under electrical stress, low film density after evaporation, and adsorption of contaminants from ambient. ${ }^{13}$

The atomic layer deposition (ALD) being a highly smooth, conformal, uniform growth process, could be a promising method of dielectric deposition for inkjet printed transistors. ${ }^{\mathbf{1 4}}$ ALD grown materials are used as a buffer layer in flexible transistors, high- $k$ dielectrics, encapsulation layer, for thin film coating, and composite materials. ${ }^{15-19}$ For the bottom-gate coplanar graphene transistors, a surface with contact angle $70-90^{\circ}$ is desirable for better adhesion between graphene and underlying dielectric. ${ }^{20}$ Zirconium oxide $\left(\mathrm{ZrO}_{2}\right)$ as a high- $k$ dielectric material can be suitable for inkjet printed transistors for its relatively hydrophobic properties. ${ }^{21}$ Previously, inkjet 
printed carbon nanotube transistor was demonstrated using solution-processed $\mathrm{ZrO}_{2}$ dielectric. ${ }^{20}$ However, thermally annealed, solution-processible $\mathrm{ZrO}_{2}$ had high leakage current, and required UV-curing for proper functioning. ${ }^{22,23}$ The chemical vapor deposition of $\mathrm{ZrO}_{2}$ from zirconium tetra-tert-butoxide requires very high temperatures $\left(380-825{ }^{\circ} \mathrm{C}\right) .{ }^{24}$ Even pulse laser deposition of $\mathrm{ZrO}_{2}$ requires high deposition temperatures (400$600{ }^{\circ} \mathrm{C}$ ) or high-temperature treatment to promote crystallinity. ${ }^{25,26} \mathrm{The}_{\mathrm{ZrO}_{2}}$ deposited from metal amide precursors can be a potential high- $k$ dielectric for printed and flexible electronics because of their low ALD temperature window (250-350 $\left.{ }^{\circ} \mathrm{C}\right)$ which many flexible substrates can sustain. ${ }^{27-29}$ The ALD$\mathrm{ZrO}_{2}$ from TDMAZr precursor was successfully deposited on graphene and nitrogen doped carbon nanotube (NCNT) nanoflakes to study the nanocomposite materials. ${ }^{30,31}$ The encapsulation layer properties for OLEDs, and dielectric properties on the gallium nitride (GaN) substrate using $\mathrm{ZrO}_{2}$ from TDMAZr precursor was studied before, but the details of growth kinetics on silicon (Si) are still lacking. ${ }^{32-34}$ All these depositions were limited to 100 cycles and did not include dielectric properties. ${ }^{27,33,34}$ Our study investigates the growth kinetics, orientation, growth saturation, and dielectric properties of $\mathrm{ZrO}_{2}$ using atomic layer deposition (ALD) from TDMAZr and water precursors. The trend of our contact angle on the $\mathrm{ZrO}_{2}$ surface with temperature was opposite to the trend shown in ref. 33. We validated and discussed our observations in context of surface roughness and surface chemistry in details. Furthermore, we demonstrated the step-by-step method of fabricating and characterizing printed graphene transistor using $\mathrm{ZrO}_{2}$ dielectric.

\section{Experimental section}

\section{$2.1 \mathrm{ZrO}_{2}$ growth process}

The $\mathrm{ZrO}_{2}$ was deposited using a plasma-enhanced atomic layer deposition (PEALD) reactor (Arradiance Gemstar-6 XT-P) on heavily n-doped silicon (100) substrate after hydrofluoric acid (HF) precleaning followed by nitrogen $\left(\mathrm{N}_{2}\right)$ dry for one minute. The substrates were put into the chamber immediately. Purge times were greater than five seconds to avoid non-self-limiting or CVD like growth or multilayer physisorption. ${ }^{27}$ To find out the conditions of growth saturation, the pulse and purge times were kept constant. TDMAZr was held at $80{ }^{\circ} \mathrm{C}$ to provide sufficient $\mathrm{Zr}$ precursor vapors in the reactor. Manifold heaters were heated at $115{ }^{\circ} \mathrm{C}$ to avoid precursor condensations. Argon was used as the carrier gas and the ALD reactor was kept at 45 mTorr pressure. One ALD cycle was completed with the following steps: (a) a $400 \mathrm{~ms}$ dose of TDMAZr, (b) a $20 \mathrm{~s}$ purge of excess TDMAZr and byproducts using $100 \mathrm{sccm}$ argon flow, (c) a $50 \mathrm{~ms}$ dose of $\mathrm{H}_{2} \mathrm{O}$, and (d) a $20 \mathrm{~s}$ argon purge of excess water and byproducts. The depositions were carried out at 150, 200, and $250{ }^{\circ} \mathrm{C}$ up to 400 cycles. The $\mathrm{ZrO}_{2}$ films were characterized using ellipsometer (Wollam M2000), atomic force microscopy (Bruker dimension ICON AFM), X-ray diffraction (Rigaku SmartLab X-ray diffractometer), CV analyzer (Keithley 590), and tensiometer (Falcon, First Ten Angstroms, Inc., Portsmouth,
VA) respectively. The following half-reactions were proposed inside the ALD reactor with TDMAZr and water precursors ${ }^{27}$

$$
\begin{aligned}
\| 2(\mathrm{OH})+\mathrm{Zr}\left(\mathrm{NMe}_{2}\right)_{4}(\mathrm{~g}) & \rightarrow \|\left(\mathrm{O}_{2} \mathrm{Zr}\left(\mathrm{NMe}_{2}\right)_{2}\right)(\mathrm{s}) \\
+ & 2 \mathrm{H}\left(\mathrm{NMe}_{2}\right)(\mathrm{g}) \\
\|\left(\mathrm{O}_{2} \mathrm{Zr}\left(\mathrm{NMe}_{2}\right)_{2}\right)(\mathrm{s})+2 \mathrm{H}_{2} \mathrm{O} & \rightarrow \|\left(-\mathrm{O}_{2} \mathrm{Zr}(\mathrm{OH})_{2}\right) \\
& +2 \mathrm{H}\left(\mathrm{NMe}_{2}\right)(\mathrm{g})
\end{aligned}
$$

|| indicates the surface of the sample. The schematic of the reactions is shown in Fig. S1 (see ESI†).

\subsection{Results and discussion}

The thickness of $\mathrm{ZrO}_{2}$ films was measured using an ellipsometer. The thickness of $\mathrm{ZrO}_{2}$ films changes linearly up to 400 cycles at different temperatures, unless it is diverged at $250{ }^{\circ} \mathrm{C}$ as shown in Fig. 1a. At the ALD temperature window $\left(250^{\circ} \mathrm{C}\right.$ for TDMAZr precursor), this aberration is expected and observed between $300-400$ cycles. Only $2.05 \mathrm{~nm}$ was grown over 100 cycles in that region. We further deposited $\mathrm{ZrO}_{2}$ up to 600 cycles (not shown) at $250{ }^{\circ} \mathrm{C}$ and the maximum thickness was $24.71 \mathrm{~nm}$. We conclude that the growth is initially linear with the number of cycles and gets saturated after 300 cycles at the ALD temperature window. The growth per cycle (GPC) is a crucial parameter to predict the film growth at different temperatures. The GPC for $\mathrm{ZrO}_{2}$ was $0.133,0.107$, and $0.084 \mathrm{~nm}$ at 150, 200, and $250{ }^{\circ} \mathrm{C}$ respectively. The GPC decreases linearly with an increase of the deposition temperatures. The GPC was 0.64 times lower at $250{ }^{\circ} \mathrm{C}$ compared to GPC at $150{ }^{\circ} \mathrm{C}$. This decline of GPC is caused by the increasing desorption of $-\mathrm{OH}$ groups with higher temperatures. The dehydroxylation for $\mathrm{ALD}-\mathrm{ZrO}_{2}$ can be described as follows: ${ }^{35}$

$$
\mathrm{OH}-\mathrm{Zr}+\mathrm{OH}-\mathrm{Zr} \rightarrow \mathrm{Zr}-\mathrm{O}-\mathrm{Zr}+\mathrm{H}_{2} \mathrm{O}
$$

As the film thickness and GPC have linear relations with the number of cycles and temperatures, the deposition rate is highly tunable in atomic scale. The hydrofluoric acid (HF) pretreatment of substrate induces a hydrophobic $-\mathrm{H}$ terminated surface on silicon. ${ }^{36}$ In our case, it is reasonable to believe an atomic layer starts growing from the very first cycle, and the large number of $-\mathrm{OH}$ nucleation sites on the silicon surface are created during the first water pulse of the ALD process. At all the deposition temperatures, $\mathrm{ALD}-\mathrm{ZrO}_{2}$ followed a similar growth process i.e. layer-by-layer growth mode. At $250{ }^{\circ} \mathrm{C}$, the absence of $-\mathrm{OH}$ sites are responsible for growth saturation which will be explained in later section.

For device applications, surface irregularity can influence adhesion and transport properties. ${ }^{37}$ The surface topology of the films was studied using atomic force microscopy (AFM). The RMS surface roughness curves in Fig. 1b, show linear trends at 150 and $200{ }^{\circ} \mathrm{C}$. However, at first, the roughness rises slightly and then reduces with the number of cycles at $250{ }^{\circ} \mathrm{C}$. This discrepancy in roughness is the result of static adatoms and the presence of residual $\mathrm{Zr}$ precursor ligands due to incomplete reaction at low temperatures. At $250{ }^{\circ} \mathrm{C}$, the adatoms are more 
(a)

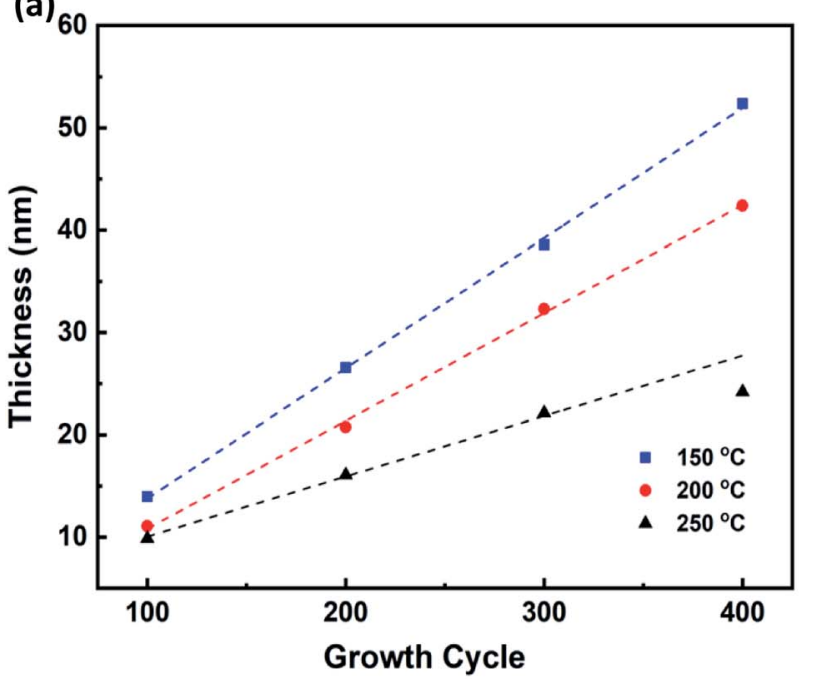

(b)

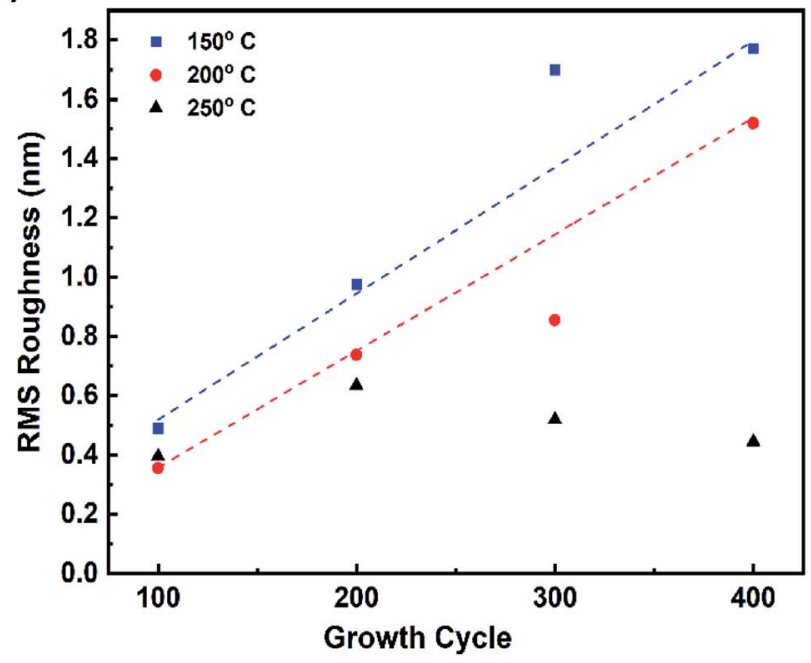

Fig. 1 (a) Ellipsometer thickness of $\mathrm{ZrO}_{2}$ at different temperatures and number of cycles, (b) RMS roughness of $\mathrm{ZrO}_{2}$ from $\mathrm{AFM}$ measurements.

mobile and the $\mathrm{Zr}$ and $\mathrm{O}$ ions occupy the positions with the lowest free energy of the crystal. ${ }^{33}$ The surfaces are highly smooth as the roughness is less than $4 \%$ of the corresponding film thickness. The 3D surface topography of $\mathrm{ZrO}_{2}$ films at $150{ }^{\circ} \mathrm{C}$ is shown in Fig. 2 using an AFM scanned area of $500 \times$ $500 \mathrm{~nm}^{2}$. Fig. 2a and b appear like tapered posts. The facets of the crystallites are more visible in Fig. 2c. The surface of Fig. 2d looks like hillocks with multiple valleys between them. These peaks are responsible for the highest surface roughness (1.77 $\mathrm{nm}$ ) among all the samples, and a clear indication of precursor agglomeration at low temperature as the thermal energy during film growth was not enough to remove the zirconium precursor ligands completely.
The film thickness is a crucial factor in determining the crystal structure and phase of $\mathrm{ZrO}_{2} \cdot{ }^{38}$ For 150 and $200{ }^{\circ} \mathrm{C}$, the thickness of the films was deliberately kept high to study the role of thickness on crystallinity. The X-ray diffraction (XRD) measurements were performed in $\mathrm{ALD}-\mathrm{ZrO}_{2}$ films of thickness $63,46.4$, and $22.3 \mathrm{~nm}$ for temperatures 150,200 , and $250{ }^{\circ} \mathrm{C}$ respectively. Fig. 3a shows the XRD spectra at various temperatures. At a low temperature $\left(150{ }^{\circ} \mathrm{C}\right)$, the structure is amorphous as no noticeable peak is found in the XRD pattern. As the temperature increases, a sharp peak starts appearing in the angular position $(2 \theta)$ of $33^{\circ}$. The intensity of the peak increases at higher temperatures. At $200^{\circ} \mathrm{C}$, a mixture of amorphous and crystalline states is present in the thin film. Nonetheless, (a)

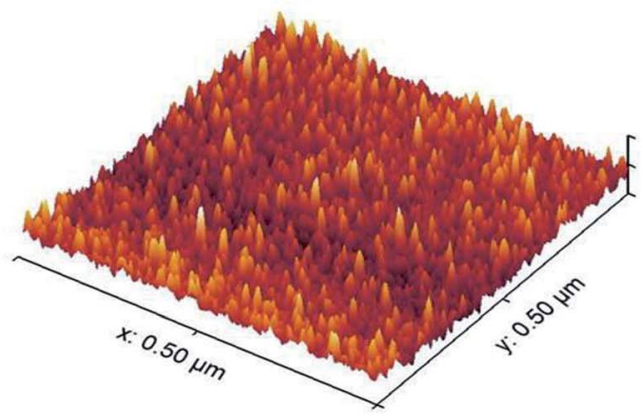

(c)

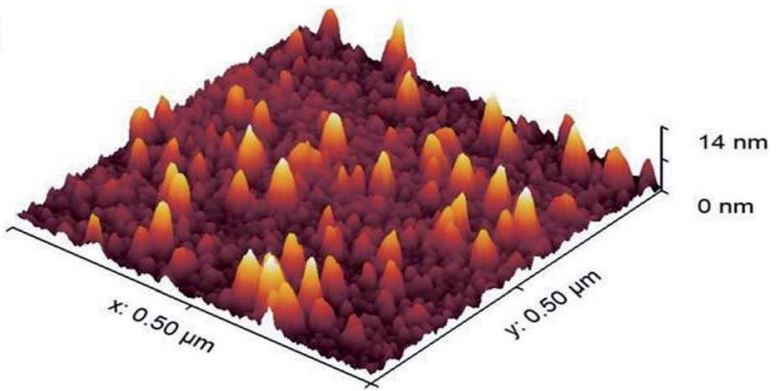

(b)

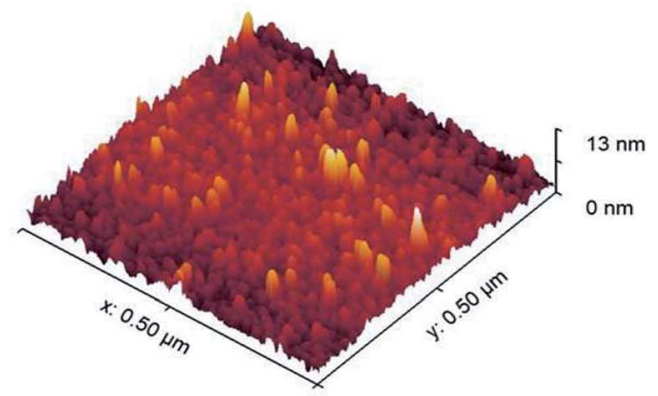

(d)

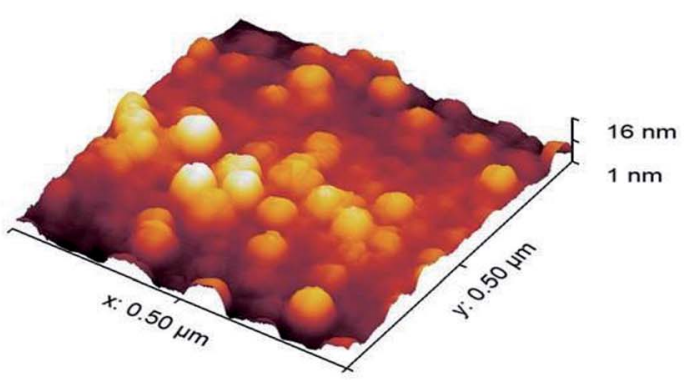

Fig. 2 AFM surface images at $150^{\circ} \mathrm{C}$ for growth cycles- (a) 100, (b) 200, (c) 300, (d) 400. 
(a)

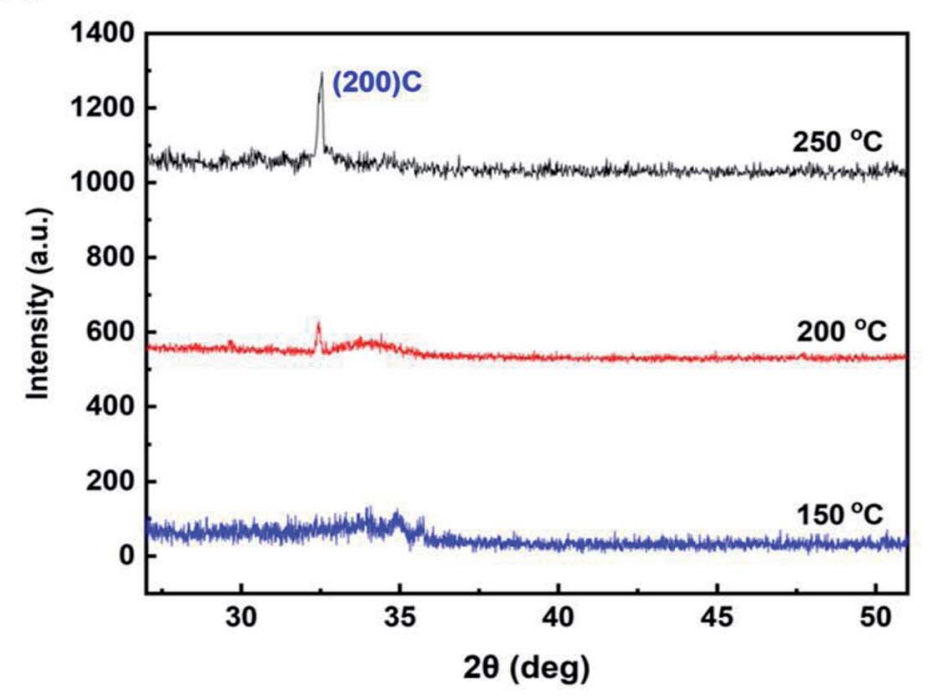

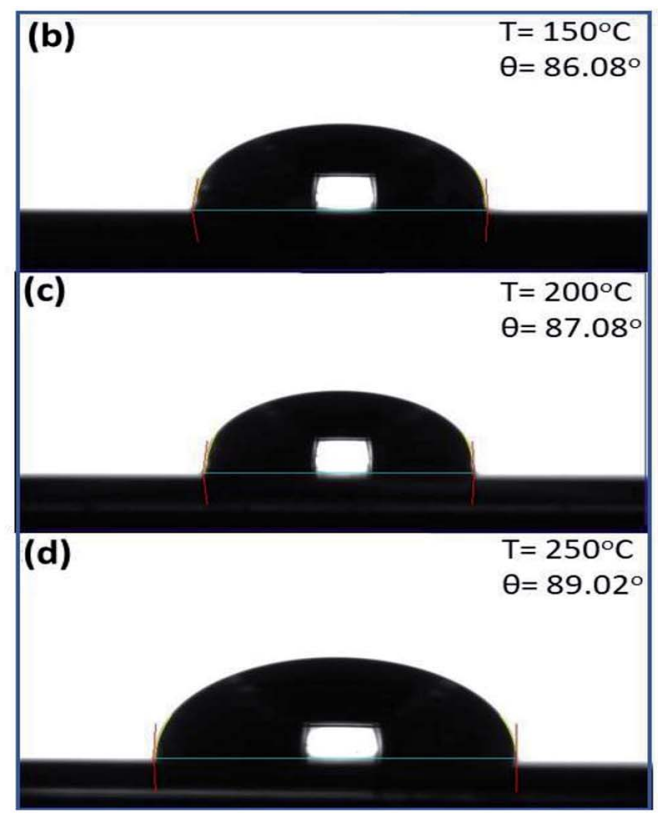

Fig. 3 (a) XRD patterns of $\mathrm{ZrO}_{2}$ at different temperatures. Measured contact angles on $\mathrm{ZrO}_{2}$ for 400 cycles at: (b) $150{ }^{\circ} \mathrm{C}$, (c) $200{ }^{\circ} \mathrm{C}$, (d) $250{ }^{\circ} \mathrm{C}$.

a sharp peak at $250{ }^{\circ} \mathrm{C}$ in XRD pattern reveals the crystalline state of the deposited $\mathrm{ZrO}_{2}$. The peaks of XRD patterns can be indexed as (200) plane with cubic phase structure. Along with deposition, the crystallinity of $\mathrm{ZrO}_{2}$ is highly tunable from amorphous to crystalline phase with temperature alteration. Instead of the film thickness, the temperature is the crucial factor for crystallinity of ALD-ZrO ${ }_{2}$. The temperature influences the surface mobility of adatoms, reaction mechanism, and the number of nucleation sites. High temperatures promote the dehydroxylation, desorption, surface adatoms mobility and ordering of the structures with minimum surface energy which in turn reduce surface roughness. These phenomena lead to the crystalline structure of solids. With specific temperature provided, less surface roughness indicates more crystalline structure. Fig. S2 in the ESI $\uparrow$ shows the variations of 2D surface topology with temperatures. The energy-dispersive spectra (EDS) confirms the presence of $\mathrm{Zr}, \mathrm{O}, \mathrm{Si}$, and reveals no chemical contamination on the films (see ESI Fig. S3 †).

A hydrophilic surface is expected to print an ink using an inkjet printer. To determine the hydrophilicity of our samples, we performed contact angle tests using water droplets as shown in Fig. 3b-d. As the contact angles are less than $90^{\circ}$, the surfaces are hydrophilic in general. As the temperature increased, the films showed more hydrophobic characteristics. Therefore, selection of proper deposition technique for $\mathrm{ZrO}_{2}$ is critical because hydrophobic $\mathrm{ZrO}_{2}$ by magnetron sputtering process was reported elsewhere. ${ }^{21}$ Our observations i.e. increase of contact angle with temperature, are quite opposite to the study of ref. 33 where a significant decrease of contact angles with temperature elevation was reported. Our claim can be refuted from the surface roughness, and dehydroxylation phenomena at higher temperatures. Water easily spreads on a hydroxylated surface. The $-\mathrm{OH}$ groups promote the hydrogen bonds with water, thus reducing the contact angle. Higher temperature leads to more dehydroxylation which reduces $-\mathrm{OH}$ nucleation sites on the deposition surface. Consequently, the deficiency of $-\mathrm{OH}$ sites increases the contact angles. Due to dehydroxylation at $250{ }^{\circ} \mathrm{C}$, there is a scarcity of $-\mathrm{OH}$ bonds and the surface is nearly hydrophobic. This also strengthens the claim that the absence of $-\mathrm{OH}$ groups are responsible for the growth saturation in $300-400$ cycles at $250{ }^{\circ} \mathrm{C}$. The desorption effect is dependent on the deposition temperature as well as the time for which the processes were carried out. At $250{ }^{\circ} \mathrm{C}$, the $-\mathrm{OH}$ nucleation sites were created during the water pulses of the ALD process. It is also true that a few -OH groups can stick to the growth surface at $250^{\circ} \mathrm{C}$. This high temperature increases the surface adatoms mobility and reorganizes the $\mathrm{Zr}-\mathrm{O}$ structures based on the minimum surface energy. There should be less defect on the crystalline ALD- $\mathrm{ZrO}_{2}$ with reduced number of $-\mathrm{OH}$ sites available for nucleation. As the process at $250{ }^{\circ} \mathrm{C}$ was carried out for $300-400$ cycles (almost 5 hours), the $-\mathrm{OH}$ groups get released (desorbed) from the surface. For longer process time, the absence of $-\mathrm{OH}$ nucleation sites are responsible for the growth saturation.

The roughness of a surface can be related to the contact angle by Wenzel's theory, ${ }^{39} \cos \left(\theta_{\mathrm{A}}\right)=r \cos \left(\theta_{\mathrm{C}}\right)$, where $\theta_{\mathrm{A}}$ is the apparent contact angle on a rough surface, $\theta_{\mathrm{C}}$ is the contact angle on a smooth surface, $r$ is the roughness factor which is the ratio of the real surface area to the projected surface area. According to Wenzel's relation, surface roughness makes the hydrophilic surface more hydrophilic, and the hydrophobic surface more hydrophobic. The roughness, real and projected surface area, and roughness factors are extracted from AFM measurements as shown in Table 1. As roughness factors are less than 1.5, Wenzel's relation is reasonable to apply in our case. ${ }^{40}$ As our samples are hydrophilic, roughness makes them more hydrophilic following Wenzel's statement. For 400 cycles, the roughness increases with temperature lowering, which 
Table 1 Surface roughness relation with contact angles is determined from AFM and tensiometer measurements

\begin{tabular}{llllll}
\hline $\begin{array}{l}\text { Temperature } \\
\left({ }^{\circ} \mathrm{C}\right)\end{array}$ & $\begin{array}{l}\text { Roughness, } \\
R_{\mathrm{q}}(\mathrm{nm})\end{array}$ & $\begin{array}{l}\text { Real surface } \\
\text { area }\left(\mathrm{nm}^{2}\right)\end{array}$ & $\begin{array}{l}\text { Projected surface } \\
\text { area }\left(\mathrm{nm}^{2}\right)\end{array}$ & Roughness factor, $r$ & $\theta_{\mathrm{A}}(\mathrm{deg})$ \\
\hline 250 & 0.446 & 252012 & 250000 & 1.008 & 89.02 \\
200 & 1.52 & 255146 & 250000 & 1.020 & 89.03 \\
150 & 1.77 & 256834 & 250000 & 1.027 & 87.13 \\
$\theta_{\mathrm{C}}(\mathrm{deg})$
\end{tabular}

enhances the real surface area and surface energy. Therefore, the surface turns more hydrophilic. Table 1 summarizes the relation between temperature, roughness, roughness factor, and contact angles.

The dielectric properties of $\mathrm{ZrO}_{2}$ are studied by capacitancevoltage and parallel conductance-voltage characteristics at 100 $\mathrm{kHz}$. The $\mathrm{ALD}-\mathrm{ZrO}_{2}$ films were deposited on n-type Si wafers with the resistivity of $0.01-0.02 \Omega \mathrm{cm}$. To evaluate the influence of the temperature on dielectric constant and interface traps, the oxide thicknesses were kept nearly identical such as 23.14, 21.17, and $22.3 \mathrm{~nm}$ for temperatures of 150,200 , and $250{ }^{\circ} \mathrm{C}$ respectively. The normalized $C-V$ curves shown in Fig. 4a were obtained using a mercury probe. The capacitor area was $7.4 \times$ $10^{-4} \mathrm{~cm}^{2}$. The $C-V$ curves have distinguishable accumulation, depletion, and inversion regions. Dielectric constants $(k)$ estimated from the electrical measurements are $7.5\left(150{ }^{\circ} \mathrm{C}\right), 10.85$ $\left(200{ }^{\circ} \mathrm{C}\right)$, and $11\left(250{ }^{\circ} \mathrm{C}\right)$ respectively. Due to crystallinity at higher temperatures, the dielectric constants improved about 1.46 times. Our observation of $k$ value is lower, but consistent with the expected value of $k$ for $\mathrm{ZrO}_{2}$ i.e. $10-25 .{ }^{41}$ For the device structures, the $k$-values were consistent with our reported dielectric constants. Ellipsometry is very sensitive to interfacial oxide, and we did not observe any signature of $\mathrm{SiO}_{X}$ growth in our ellipsometry data. All our mean-square-error (MSE) values were less than 5. The breakdown field of the $\mathrm{ALD}-\mathrm{ZrO}_{2}$ was $\sim 1$ $\mathrm{MV} \mathrm{cm}^{-1}$. We also examined the hysteresis behavior of the ALD$\mathrm{ZrO}_{2}$ dielectric in Fig. S4 (see ESI $\dagger$ ). The CV curves show a small hysteresis. Low hysteresis means there exists a good quality of $\mathrm{ALD}-\mathrm{ZrO}_{2}$ dielectric/Si semiconductor interface. This low hysteresis is either due to the charge trapping in the $\mathrm{ZrO}_{2}$ or defect in the channel layer. Interestingly, the optical band gap calculated from the ellipsometer was fixed approximately at $4.82 \mathrm{eV}$ for all our samples irrespective of the deposition temperatures, number of cycles, and crystal structure.

The conductance-voltage $\left(G_{\mathrm{p}} / \omega-V\right)$ characteristics of MOS capacitors are shown in Fig. 4b. Conductance curves can be utilized to calculate the interface state density using the HillColeman method as following: ${ }^{42}$

$$
N_{\mathrm{ss}}=\frac{2}{q A} \frac{\frac{G_{\mathrm{m}, \max }}{\omega}}{\left(\frac{G_{\mathrm{m}, \max }}{\omega C_{\mathrm{ox}}}\right)^{2}+\left(1-\frac{C_{\mathrm{m}}}{C_{\mathrm{ox}}}\right)^{2}}
$$

where $A$ is capacitor area, $G_{\mathrm{m} \text {,max }}$ is the peak value of measured capacitance, $C_{\mathrm{m}}$ is the corresponding measured capacitance, and $C_{\mathrm{Ox}}$ is the capacitance of insulation layer in the strong accumulation layer. The calculated interface trap densities are $9.23 \times 10^{13}\left(150^{\circ} \mathrm{C}\right), 6.15 \times 10^{13}\left(200{ }^{\circ} \mathrm{C}\right)$, and $5.95 \times 10^{13}(250$ $\left.{ }^{\circ} \mathrm{C}\right) \mathrm{eV}^{-1} \mathrm{~cm}^{-2}$ respectively. The interface traps are highest at $150{ }^{\circ} \mathrm{C}$ because of the defects in the $\mathrm{ZrO}_{2}$ films as the $\mathrm{Zr}$ precursor ligands did not remove completely, which is evident in the $C-V$ curve flat-band shift. The interface traps at 200 and $250{ }^{\circ} \mathrm{C}$ are in the same order of magnitude reported for thermally evaporated hafnium oxide which was cured at 350 to $450{ }^{\circ} \mathrm{C} .{ }^{43}$ The traps in $\mathrm{ZrO}_{2}$ can be reduced using doping or high temperature treatment after the deposition. ${ }^{44,45}$ Our goal is to use the $\mathrm{ALD}-\mathrm{ZrO}_{2}$ for printed electronics, so all our samples were as-deposited. To avoid high interface traps and growth saturation, subsequent depositions of $\mathrm{ZrO}_{2}$ for device fabrication were carried out at $200{ }^{\circ} \mathrm{C}$.

\subsection{Device fabrication}

The details of graphene ink preparation, optical absorption spectrum, and Raman spectra are discussed in the ESI (Fig. S5 $\dagger$ ). The reliability of a gate dielectric depends on its ability to modulate the drain current and provide low gate leakage. Fig. 5a and b show the schematic and microscopic image of the bottom gate coplanar transistor structure with $\mathrm{ALD}-\mathrm{ZrO}_{2}$ dielectric and inkjet printed graphene. The heavily doped n-type Si (100) wafer was used as the back-gate as well as the substrate. A $\mathrm{ZrO}_{2}$ dielectric layer of $46.4 \mathrm{~nm}$ thick was deposited at $200{ }^{\circ} \mathrm{C}$. The source (S) and drain (D) electrodes were printed using silver nanoparticle ink (Novacentrix, Metalon ${ }^{\circ}$ JS-B40G) followed by a thermal curing at $150{ }^{\circ} \mathrm{C}$ for $30 \mathrm{~min}$. The printed silver developed a well-defined pattern on $\mathrm{ZrO}_{2}$ which was confirmed from the microscopic and SEM images. The silver adhered to the $\mathrm{ZrO}_{2}$ surface quite well as depicted in Fig. $5 \mathrm{~b}$. The width of the source and drain electrodes was 258.33 $\mu \mathrm{m}$ and the channel length was $113.33 \mu \mathrm{m}$. Multiple printing passes (12 times) of the graphene ink were performed to create a percolation cluster between source and drain terminals. For 12 printing passes, the average thickness of the printed graphene layers was approximately $53 \mathrm{~nm}$. This satisfies the percolation threshold of printed graphene thickness of $25 \mathrm{~nm}$ for back-gated device. ${ }^{\mathbf{1 1}}$ The graphene ink was prepared using terpineol and cyclohexanone solvents which are polar solvents. Using polar solvents, it is difficult to print a regular pattern on a hydrophobic surface. In a hydrophobic surface, they either form small droplets in the defined region, or the pattern collapses during curing. Despite the nearly hydrophobic behavior of the surfaces, we printed and cured graphene on the $\mathrm{ZrO}_{2}$ surface successfully. Fig. 5c shows the SEM image of the graphene percolating network. The projected area has good coverage with crumpling graphene flakes.

Fig. $5 \mathrm{~d}$ depicts the output $\left(I_{\mathrm{d}}\right.$ versus $\left.V_{\mathrm{d}}\right)$ characteristics of the printed graphene transistor for several values of $V_{\mathrm{g}}$. The gate 
(a)

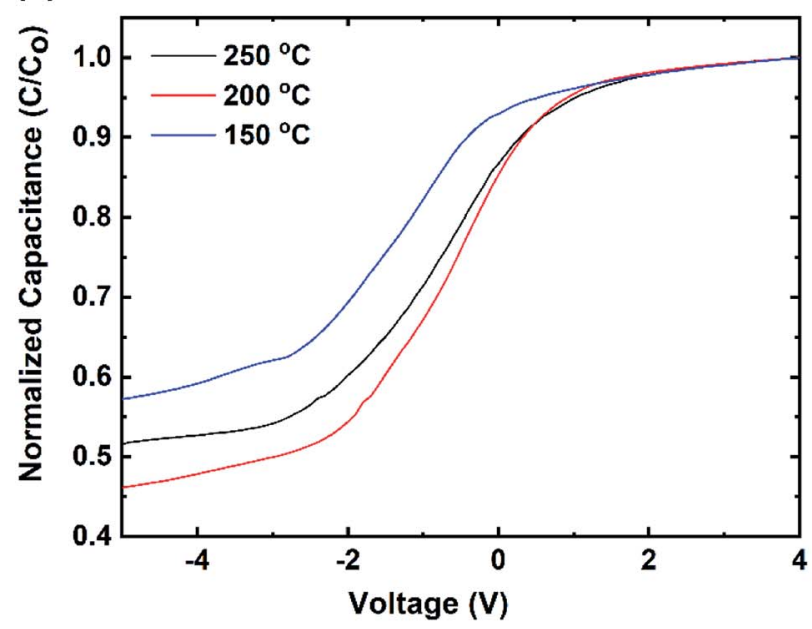

(b)

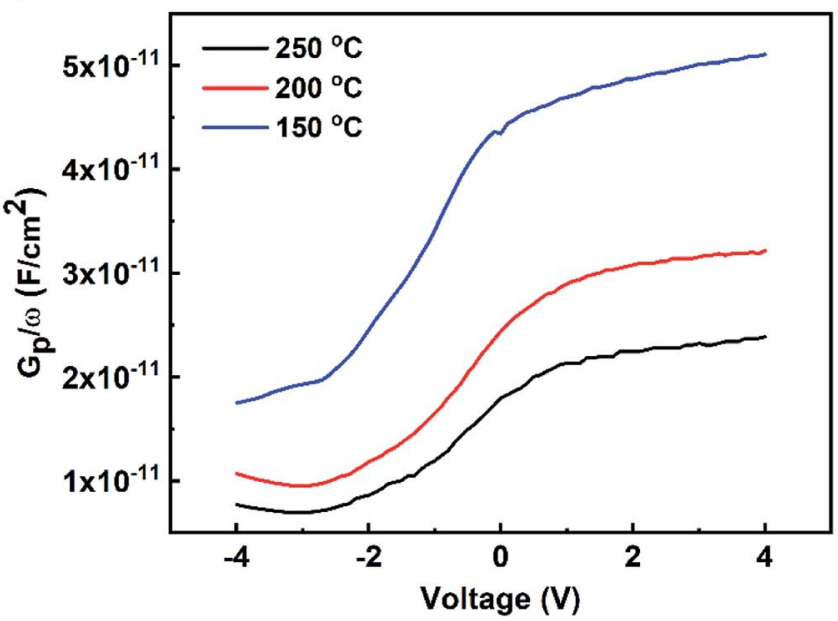

Fig. 4 (a) Capacitance-voltage behaviors of $\mathrm{Hg} / \mathrm{ZrO}_{2} / \mathrm{Si}-\mathrm{n}$ (100) MOS capacitor, (b) $G_{\mathrm{p}} / \omega$ curves at different voltages.

voltage was changed from 0.5 to $-1.5 \mathrm{~V}$ with a decrement of $-0.5 \mathrm{~V}$. The drain voltage also varied from 0 to $-2 \mathrm{~V}$ for each value of $V_{\mathrm{g}}$. The drain characteristics are linear. The trace of $I_{\mathrm{d}^{-}}$ $V_{\mathrm{d}}$ goes higher as the gate bias changes from positive to more negative. As $I_{\mathrm{d}}$ increases with negative $V_{\mathrm{g}}$, the transistor is of ptype. At $V_{\mathrm{d}}=-2 \mathrm{~V}$, the drain current changes from -5.85 to $-7.17 \mu \mathrm{A}$ for a $V_{\mathrm{g}}$ variation of $2 \mathrm{~V}$. This implies that the fieldeffect behavior due to the application of voltage on a thin $\mathrm{ZrO}_{2}$ layer is distinguishable from the output characteristics.
Transfer characteristics of printed graphene transistor is shown in Fig. S6 (see ESI $\dagger$ ). Transfer characteristics were measured at the drain bias of $-1,-1.5$, and $-2 \mathrm{~V}$ respectively. The gate-source leakage current $\left(I_{\mathrm{sg}}\right)$ was very small (less than $20 \mathrm{nA}$ ). The drain current $I_{\mathrm{d}}$ increases as the gate voltage goes from positive to negative. The charge neutrality (Dirac) point was outside of our measurement range. The unintentional doping may obscure the Dirac point in our measurement range. However, the gate modulation is well pronounced in the (a)
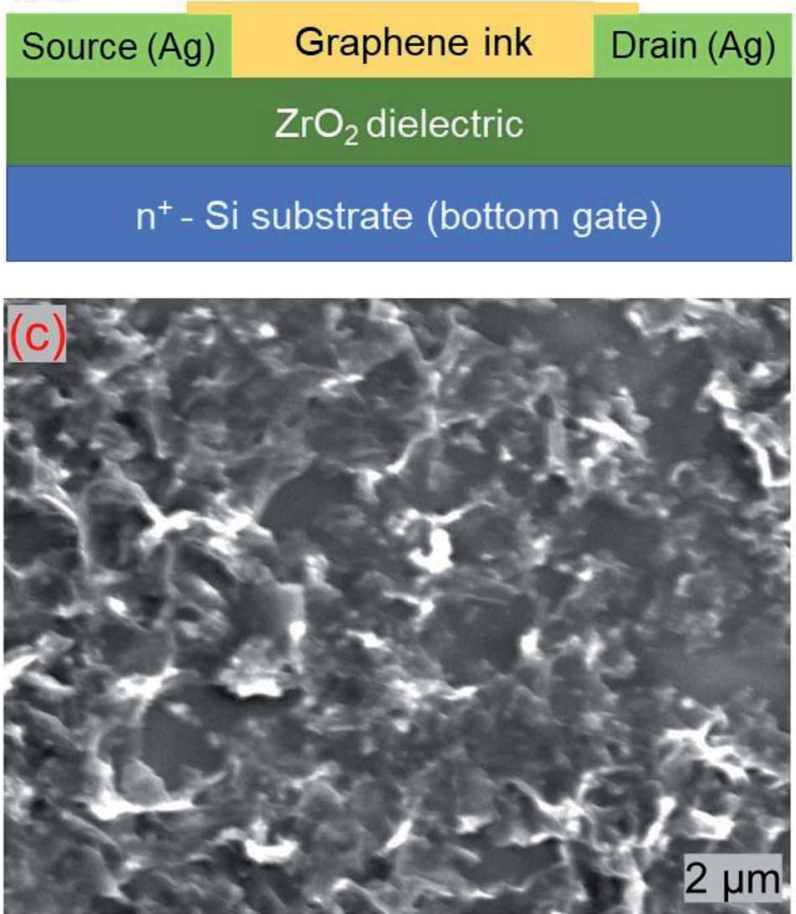

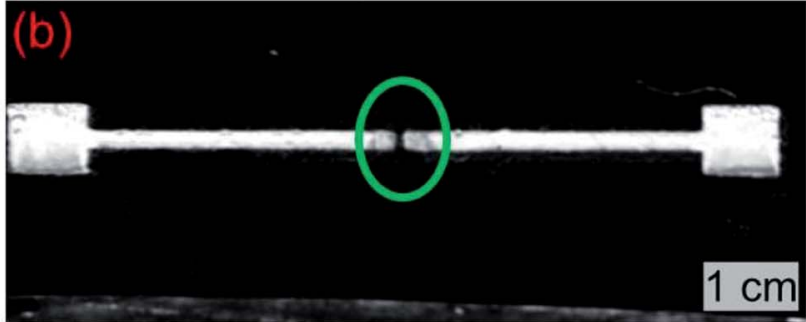

(d)

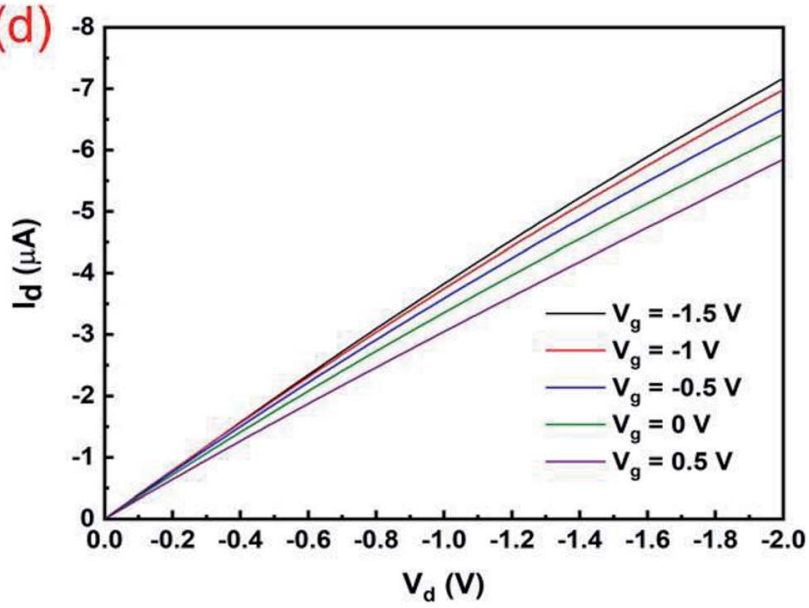

Fig. 5 (a) Schematic of bottom-gate coplanar transistor, (b) microscopic image of printed graphene transistor, (c) SEM image of printed graphene, and (d) output characteristics of an inkjet-printed graphene transistor. 
transfer characteristics at different drain biases. At $V_{\mathrm{d}}=-2 \mathrm{~V}$, a current ON/OFF ratio of 1.46 is obtained from Fig. S6 in the ESI. $\uparrow$ It is well-known that graphene does not have a band gap (zero band gap) and its transistor never turns off. So, it is unlikely to get a perfect off state and ON/OFF switching behavior from a graphene transistor. Small ON/OFF ratio and non-saturation are problems with all inkjet printed graphene transistors, due to the absence of bandgap in graphene. The effective mobility $\mu$ can be derived from the slope of the transfer characteristics using $\mu=\left(L \times g_{\mathrm{m}} / W \times C_{\mathrm{ox}} \times V_{\mathrm{d}}\right)$, where $L(113.33$ $\mu \mathrm{m})$ and $W(258.33 \mu \mathrm{m})$ are channel length and width, $C_{\mathrm{ox}}$ is the gate capacitance $\left(\approx 200 \mathrm{nF} \mathrm{cm}{ }^{-2}\right)$, and $g_{\mathrm{m}}=\mathrm{d} I_{\mathrm{d}} / \mathrm{d} V_{\mathrm{g}}$ is the transconductance $(0.887 \mu \mathrm{S})$. The estimated device mobility is $\approx 1 \mathrm{~cm}^{2} \mathrm{~V}^{-1} \mathrm{~s}^{-1}$. For our graphene transistor, the current $\mathrm{ON} /$ OFF ratio and mobility is lower than the printed graphene transistor reported in ref. 11 but higher than the one reported in ref. 10. However, our results are still comparable to other inkjet printed graphene transistors. ${ }^{46}$ Therefore, the ALD grown thin oxide layers are suitable for low-voltage inkjet printed transistors.

\section{Conclusion}

A comprehensive study on growth kinetics and dielectric properties of the $\mathrm{ALD}-\mathrm{ZrO}_{2}$ is conducted from TDMAZr precursor. Low-temperature growth of $\mathrm{ZrO}_{2}$ was achieved along with low roughness and high dielectric constant for different growth conditions. Linear relations of thickness and roughness were observed with growth cycles at different temperatures. The ALD temperature window for $\operatorname{Zr}\left(\mathrm{NMe}_{2}\right)_{4}$ precursor was determined from the growth saturation for 400 cycles at $250{ }^{\circ} \mathrm{C}$. The crystallinity, the cubic phase, and the orientation in the (200) direction were observed at higher temperatures from the XRD patterns. The interface traps are due the defects in the $\mathrm{ZrO}_{2}$ films. In general, all our oxide surfaces were hydrophilic as the contact angles were less than $90^{\circ}$. The trend of contact angle change with temperature change is contrary to the previous report, and therefore opens a new venue for research in this direction. Graphene thin films of given patterns were deposited through inkjet printing on $\mathrm{ZrO}_{2}$ successfully. No significant differences of inkjet printed graphene on $\mathrm{ZrO}_{2}$ were noticed from Raman spectra. Finally, the printing of graphene transistors was realized using the bottom-gate coplanar structure with $\mathrm{ZrO}_{2}$ gate dielectric. A printed graphene transistor with a current on-off ratio of 1.46 at $V_{\mathrm{d}}=-2 \mathrm{~V}$ was achieved.

\section{Conflicts of interest}

The authors declare no conflict of interest.

\section{Acknowledgements}

This work was supported by Northrop Grumman Grant no. 2206730 and the National Science Foundation under MRI Grant No. 1625778. This work was also supported by the MSEC PhD program and Thesis Support Fellowship at Texas State University, San Marcos. We thank Dr Ravi Droopad, Dr Casey Smith, and Dr Dmitry Lyashenko for provided training and useful discussions.

\section{References}

1 M. Singh, H. M. Haverinen, P. Dhagat and G. E. Jabbour, $A d v$. Mater., 2010, 22, 673-685.

2 J. Chang, X. Zhang, T. Ge and J. Zhou, Org. Electron., 2014, 15, 701-710.

3 S. Chung, S. O. Kim, S. K. Kwon, C. Lee and Y. Hong, IEEE Electron Device Lett., 2011, 32, 1134-1136.

4 P. M. Grubb, H. Subbaraman, S. Park, D. Akinwande and R. T. Chen, Sci. Rep., 2017, 7, 1202.

5 B. Huber, P. Popp, M. Kaiser, A. Ruediger and C. Schindler, Appl. Phys. Lett., 2017, 110, 143503.

6 T. M. Eggenhuisen, Y. Galagan, a. F. K. V. Biezemans, T. M. W. L. Slaats, W. P. Voorthuijzen, S. Kommeren, S. Shanmugam, J. P. Teunissen, A. Hadipour, W. J. H. Verhees, S. C. Veenstra, M. J. J. Coenen, J. Gilot, R. Andriessen and W. a. Groen, J. Mater. Chem. A, 2015, 3, 7255-7262.

7 L. Zhou, L. Yang, M. Yu, Y. Jiang, C. F. Liu, W. Y. Lai and W. Huang, ACS Appl. Mater. Interfaces, 2017, 9, 40533-40540.

8 A. Moya, E. Sowade, F. J. del Campo, K. Y. Mitra, E. Ramon, R. Villa, R. R. Baumann and G. Gabriel, Org. Electron., 2016, 39, 168-176.

9 D. Soltman and V. Subramanian, Langmuir, 2008, 24, 22242231.

10 J. Li, F. Ye, S. Vaziri, M. Muhammed, M. C. Lemme and M. Östling, Adv. Mater., 2013, 25, 3985-3992.

11 F. Torrisi, T. Hasan, W. Wu, Z. Sun, A. Lombardo, T. S. Kulmala, G. W. Hsieh, S. Jung, F. Bonaccorso, P. J. Paul, D. Chu and A. C. Ferrari, ACS Nano, 2012, 6, 2992-3006.

$12 \mathrm{~W} . \mathrm{Xu}, \mathrm{H}$. Li, J. Bin $\mathrm{Xu}$ and L. Wang, ACS Appl. Mater. Interfaces, 2018, 10, 25878-25901.

13 M. A. Dominguez, O. Obregon and J. A. Luna-Lopez, J. Alloys Compd., 2016, 688, 893-896.

14 J. Leppäniemi, K. Eiroma, H. Majumdar and A. Alastalo, ACS Appl. Mater. Interfaces, 2017, 9, 8774-8782.

15 J. Sheng, H. J. Jeong, K. L. Han, T. H. Hong and J. S. Park, J. Inf. Disp., 2017, 39, 1.

16 R. Zazpe, M. Knaut, H. Sopha, L. Hromadko, M. Albert, J. Prikryl, V. Gärtnerová, J. W. Bartha and J. M. Macak, Langmuir, 2016, 32, 10551-10558.

17 X. Meng, Y. Zhong, Y. Sun, M. N. Banis, R. Li and X. Sun, Carbon, 2011, 49, 1133-1144.

18 P. D. Ye, G. D. Wilk, J. Kwo, B. Yang, H. J. L. Gossmann, M. Frei, S. N. G. Chu, J. P. Mannaerts, M. Sergent, M. Hong, K. K. Ng and J. Bude, IEEE Electron Device Lett., 2003, 24, 209-211.

19 Y. Q. Yang, Y. Duan, P. Chen, F. B. Sun, Y. H. Duan, X. Wang and D. Yang, J. Phys. Chem. C, 2013, 117, 20308-20312.

20 D. W. Park, S. Mikael, T. H. Chang, S. Gong and Z. Ma, Appl. Phys. Lett., 2015, 106, 102106.

21 U. S. Patel, K. H. Patel, K. V. Chauhan, A. K. Chawla and S. K. Rawal, Proc. Technol., 2016, 23, 336-343. 
22 B. Kim, S. Jang, P. L. Prabhumirashi, M. L. Geier, M. C. Hersam and A. Dodabalapur, Appl. Phys. Lett., 2013, 103, 082119.

23 Y. M. Park, A. Desai, A. Salleo and L. Jimison, Chem. Mater., 2013, 25, 2571-2579.

24 D. J. Burleson, J. T. Roberts, W. L. Gladfelter, S. A. Campbelland and R. C. Smith, Chem. Mater., 2002, 14, 1269-1276.

25 A. O. Dikovska, G. Atanasova, G. Avdeev and V. Strijkova, J. Phys.: Conf. Ser., 2016, 012024.

26 M. F. Al-Kuhaili and S. M. a. Durrani, J. Alloys Compd., 2011, 509, 9536-9541.

27 D. M. Hausmann, E. Kim, J. Becker and R. G. Gordon, Chem. Mater., 2002, 14, 4350-4358.

28 Dupont Kapton data sheet (http:/www.dupont.com/content/ dam/dupont/products-and-services/membranes-and-films/ polyimde-films/documents/DEC-Kapton-summary-ofproperties.pdf).

29 D. Y. Kim, S. Lee, Z.-H. Lin, K. H. Choi, S. G. Doo, H. Chang, J.-Y. Leem, Z. L. Wang and S.-O. Kim, Nano Energy, 2014, 9, 101-111.

30 J. Liu, X. Meng, Y. Hu, D. Geng, M. N. Banis, M. Cai, R. Li and X. Sun, Carbon, 2013, 52, 74-82.

31 J. Liu, X. Meng, M. N. Banis, M. Cai, R. Li and X. Sun, J. Phys. Chem. C, 2012, 116, 14656-14664.

32 Z. Chen, H. Wang, P. Xiong, P. Chen, H. Li, Y. Liu and Y. Duan, J. Phys. Chem. C, 2017, 121, 4714-4719.
33 Y. Duan, F. Sun, Y. Yang, P. Chen, D. Yang, Y. Duan and X. Wang, ACS Appl. Mater. Interfaces, 2014, 6, 3799-3804.

34 Y. C. Byun, J. G. Lee, X. Meng, J. S. Lee, A. T. Lucero, S. J. Kim, C. D. Young, M. J. Kim and J. Kim, Appl. Phys. Lett., 2017, 111, 082905.

35 M. Cassir, F. Goubin, C. Bernay, P. Vernoux and D. Lincot, Appl. Surf. Sci., 2002, 193, 120-128.

36 J. Damlencourt, O. Renault, F. Martin, M. Semeria, T. Billon and F. Bedu, Appl. Phys. Lett., 2005, 86, 141913.

37 M. Li, T. Marszalek, K. Müllen and W. Pisula, ACS Appl. Mater. Interfaces, 2016, 8, 16200-16206.

38 S. Sayan, N. V. Nguyen, J. Ehrstein, T. Emge, E. Garfunkel, M. Croft, X. Zhao, D. Vanderbilt, I. Levin, E. Gusev, et al., Appl. Phys. Lett., 2005, 86, 152902.

39 R. N. Wenzel, Ind. Eng. Chem., 1936, 28, 988-994.

40 Y. Tamai and K. Aratani, J. Phys. Chem., 1972, 76, 3267-3271. 41 D. Panda and T.-Y. Tseng, Thin Solid Films, 2013, 531, 1-20. 42 W. Hill and C. Coleman, Solid-State Electron., 1980, 23, 987993.

43 N. Chowdhury, R. Garg and D. Misra, Appl. Phys. Lett., 2004, 85, 3289-3291.

44 A. Tamm, J. Kozlova, T. Arroval, L. Aarik, P. Ritslaid, H. García, H. Castán, S. Dueñas, K. Kukli and J. Aarik, Chem. Vap. Deposition, 2015, 21, 181-187.

45 A. Zoolfakar, Mater. Res. Innovations, 2009, 13, 161-164.

46 C. Petridis, Y.-H. Lin, K. Savva, G. Eda, E. Kymakis, T. Anthopoulos and E. Stratakis, Appl. Phys. Lett., 2013, 102, 093115. 